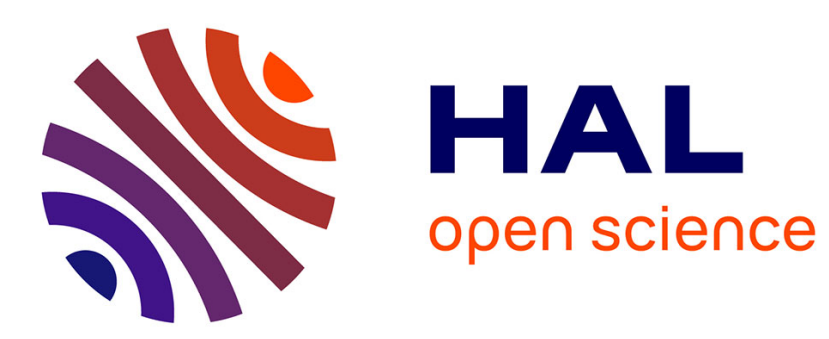

\title{
Hospital Ownership, Reimbursement Systems and Mortality Rates
}

Carine Milcent

\section{To cite this version:}

Carine Milcent. Hospital Ownership, Reimbursement Systems and Mortality Rates. Health Economics, 2005, 14 (11), pp.1151-1168. 10.1002/hec.1010 . halshs-00754053

HAL Id: halshs-00754053

https://hal-pjse.archives-ouvertes.fr/halshs-00754053

Submitted on 10 Jan 2019

HAL is a multi-disciplinary open access archive for the deposit and dissemination of scientific research documents, whether they are published or not. The documents may come from teaching and research institutions in France or abroad, or from public or private research centers.
L'archive ouverte pluridisciplinaire HAL, est destinée au dépôt et à la diffusion de documents scientifiques de niveau recherche, publiés ou non, émanant des établissements d'enseignement et de recherche français ou étrangers, des laboratoires publics ou privés. 


\title{
Hospital Ownership, Reimbursement Systems
}

\author{
and Mortality rates*
}

October 19, 2004

\footnotetext{
*I am grateful for the helpful comments of Andrew Jones, Alberto Holly, Jean Pinquet, Laurent Gobillon, Andrew Clark and Ana Prieto. My thanks also go to participants in the Twelfth European Workshop on Econometrics and Health Economics and to the referees. This study was funded in part by grants from the DREES (Direction de la Recherche, des Etudes, de l'Evaluation et des Statistiques), of the French Ministry of Labor and Solidarity.
} 


\begin{abstract}
This paper analyses the effect of hospital type on mortality rates. Statistical results on mortality rates by hospital type (ownership and system of reimbursement) are subject to serious misinterpretation. From the statistical results we could conclude that the incentive created by fee-for-service reimbursement yield a four-point reduction in the mortality rate. However, this ranking of hospital quality is completely dependent on the characteristics and illness severity of patients. The calculation of mortality rates by age structure crossed with sex totally changes the ranking. To take this difficulty into account, we use an innovative duration model applied to panel data. We consider a duration model with both patient and hospital unobserved heterogeneity. No distributional assumptions are made regarding the latter. By taking into account observable and unobservable patient heterogeneity, we control the fact that patients admitted to the private sector can be different in terms of disease severity than patients admitted to the public sector. We find that the hospital type effect on instantaneous death probability depends more on the capacity to perform innovative procedures than on the system of reimbursement and/or ownership. However, hospitals in the private sector both provide more innovative procedures and are more likely to adopt innovations. As such, private sector hospitals provide a better quality of care, measured by the probability of dying. Nevertheless, heterogeneity within hospitals is greater in for-profit hospitals than in other types of hospital. This suggests that by choosing a for-profit hospital, patients have, on average, a lower instantaneous probability of dying but are less sure about the quality of the hospital.
\end{abstract}

Key W ords: Hospitals, Mortality, and Competing Risks M odel 


\section{Introduction}

This paper evaluates the effect of differences in hospital reimbursement and ownership on in-patient mortality. This question is tackled with respect to two aspects of the literature: first, ownership and hospital performance and, second, the way to measure the quality of care.

There is an ongoing debate about the effect of ownership on hospital performance. One idea is that a profit incentive may improve efficiency and, perhaps, observable quality (Hansman, 1996). Theory predicts that the for-profit organizational form is efficient due to high-powered incentives. In early work, Arrow (1963) observed that non-profit organizations might be a socially optimal response to incomplete markets. Other theorical work has shown that the non-profit form may be socially inferior or equivalent to the for-profit form, even if markets are incomplete (Newhouse, 1970 ; Pauly and Redish, 1973).

Many empirical studies have examined the effects of hospital ownership on performance (Cutler et al., 1998; Goworisakaran and Town, 1999; McClellan and Staiger, 2000; Silverman and Skinner, 2001, and Sloan et al., 1999). Most of these conclude that hospital ownership has little or no effect on performance indicators. Picone et al. (2002) analyse the effects of changes in hospital ownership from government or private non-profit status to for-profit status and vice versa. They conclude that no decline in quality is observed after hospitals switch from for-profit to government or private non-profit status. However, after conversion to for-profit status, in-patient mortality increases while hospital profitability rises markedly and staff numbers fall. Kessler and McClellan (2002) find that areas with some for-profit hospitals have a lower level (around 2.4\%) of hospital expenditure but virtually the same patient health outcomes.

The incentive to maximise profit can be correlated with hospital ownership. For-profit hospitals have a strong incentive to maximize profit. This is why they compete with other 
hospitals for some patients. The literature on the effect of hospital competition is thinner. Kessler and McClellan (2000) find that greater competition increased patient mortality from 1986 to 1989 but decreased patient mortality from 1991 to 1994. Goworisakaran and Town (2002) examine the effects on hospital quality of competition for patients with different types of insurance. The outcome variable for hospital quality is the risk-adjusted hospital mortality rate for patients with Acute Myocardial Infarction or Pneumonia. Their findings imply different relationships between competition and hospital quality: an increase in the degree of competition decreases the risk-adjusted hospital mortality rate for HMO patients but, conversely, increases mortality for Medicare patients. Shortell and Hughes (1998), and Ho and Hamilton (2000a) find no significant effect of hospital competition on quality. Finally, Propper, Burgess and Green (2002) find that increased competition between hospitals treating heart attacks in Britain reduced mortality rates.

In France, hospital care can be provided by the public or the private sector. Patients have access to all hospitals working in or belonging to the public sector, but private sector hospitals can select patients. In addition, the public sector is under a global budget system. Hospitals of the private sector are paid by fee-for-service. Therefore, these differences suggest that hospitals have different incentives to provide care to patients. Futhermore, there are four kinds of hospital ownership systems: university hospitals, local hospitals, not-for-profit hospitals, and for-profit hospitals.

The goal of this paper is to evaluate the effect of ownership and system of reimbursement on hospital quality in France. Most of the existing literature measures hospital quality through the mortality rate accounting for the sorting of patients. In 1986, the US Health Care Financing Administration identified hospitals in which the actual death rate differed from the predicted rate, on the basis of diagnosis and demographic data. The mortality rate was obtained after adjustments for the severity of illness, and this work was carried 
out with respect to three pathologies: cerebrovascular accident, pneumonia and myocardial infarction (Dubois et al., 1987). Many studies also use the mortality rate adjusted by the severity of illness to judge the quality of the hospital (Geweke et al. (2003), Hartz et al. (1989) and Allison (2000)). One key limitation is that these studies do not take into account the possible correlation between mortality rates and the length of stay (Hamilton and Hamilton, 1987). To address this limitation, we use a duration model with multiple destinations.

The mortality rate is not the only quality of care measure which can be used to assess hospital quality. Another is the level of hospital investment. In this study, we assess not only the relationship between mortality and ownership and reimbursement systems, but also with the level of hospital investment. In the private sector, these investments depend, at least in part, on the return hospitals receive. In the public sector, investment depends on the decision of the public regulator. In practice, investment in innovative procedures tends to be allocated first to university hospitals. In this paper, we use the rate of innovative procedures by hospital.

We used unbalanced panel data. The dataset contains all French hospitals in the private and public sectors. The level of observation is the patient, who is admitted to the hospital from her/his residence. Her/his discharge can be death or return home. The pathology used in this study is Acute Myocardial Infarction (i.e. heart attack). By type, the mortality rate is almost $15 \%$ for local public hospitals and less than $7 \%$ for for-profit hospitals. It is easy to conclude that the incentives created by ownership allow an 8 point reduction in the mortality rate, which seems huge! Our bottom line is that statistical results on the mortality rate by ownership or system of reimbursement are easy to misinterpret. This ranking of hospital quality is completely dependent on patient characteristics. When we focus on the mortality rate by age structure crossed with sex, the ranking is totally changed. 
Local public hospitals, which have the highest mortality rate over the whole sample, have one of the lowest rates for male patients aged under 80 . This clearly shows the danger in making judgements according to the raw statistical mortality rate by hospital. This conclusion is in line with one of the key results of the large literature on the measurement of quality in health care. McClellan and Staiger (1999) show that the ranking of hospitals is extremely susceptible to unobserved differences in the case-mix of patients because of the small sample of patients seen across providers. Hospital rankings can be extremely variable even with relatively large (50-60) sample sizes per hospital.

We have to take patient characteristics into account in order to have a measure of hospital inefficiency. For this purpose, we use a two step method that accounts for observed and unobserved patient characteristics, and unobserved hospital efficiency. This method allows us to calculate the inefficiency heterogeneity between hospital types on one hand, by controling for patient characteristics, and on the other hand, to account for the correlation between the adjusted mortality rate and the length of stay. In a first step, the duration model estimation includes hospital specific dummy variables in order to control for fixed differences in hospital quality. In a second step, we use the estimated coefficient on the hospital type dummy to estimate the hospital type-outcome relationship. Hospital types are established according to the system of reimbursement and ownership. Hence the estimated probabilities of mortality depend on the system of reimbursement and ownership. Moreover, from a variance analysis in the second step, we identify the variance of quality inefficiency between hospitals for different systems of reimbursement and ownership. This is a relatively novel approach to the problem.

The first feature of the empirical framework is that over $50 \%$ of the in-death rate variance is explained by patients' sex and age. Moreover, we assess the effect of the system of reimbursement and ownership on the probability of in-death. Under private ownership, 
the system of reimbursement by fee-for-service is associated with a lower conditional probability of in-death. For hospitals paid by global budget, hospital ownership does not affect the conditional probability of in-death. Judging the effect of investment is complicated because of the strong correlation between hospital ownership and innovative procedures. Last, the variance analysis shows that inefficiency heterogeneity between for-profit hospitals is much more important than for other types of hospital. These results suggest that being admitted into a for-profit hospital has two consequences: a lower risk of death, but greater uncertainty about hospital quality.

Section 2 describes the data, the variables, and the first statistical results, and provides the theoretical background. In section 3 we present our empirical specification. Section 4 discuss our results, and section 5 concludes.

\section{Data and preliminary evidence}

The primary source of data for this study is the French national database from the PMSI (Programme de Médicalisation des Systèmes d'Informations). These data provide records for all patients discharged from any French acute-care hospital during the year 1997. This is the first year to include both the public and private sectors ( $80 \%$ coverage for the latter). In the dataset, the patient is admitted in the hospital from her/his residence and her/his discharge can be death or return home.

We limit our study to one single disease because there is evidence that the relation between mortality and covariates is disease specific (See Wray and alii, 1997). We choose acute myocardial infarction (heart attack) in particular for two reasons. First of all, this is an ischemic desease, the primary cause of mortality in France. Second, in-hospital death is a relatively frequent outcome for heart attack, which makes it an interesting disease to examine using hospital discharge records. Moreover, mortality from AMI has been widely 
used to assess the quality of care of hospitals in the US health market and was published as a measure of quality for UK hospitals for the first time in 1999 (Propper and alii, 2002).

The dataset is ideally suited for our purpose because it contains a large base of patients (28,410 individual stays) and contains multiple hospitals in every size and ownership class (287 public and private hospitals for heart attacks).

\subsection{A set of inclusion criteria}

The sample was selected through a set of inclusion criteria. The first criterion is that the ICD-10-CM disease codes specified in the discharge data is that for heart attack disease. There is substantial nonrandom variation across hospitals in the way in which the ICD10 diagnosis is recorded. Furthermore, we use the French DRGs code to complete this selection.

The second criterion is that the patient is over 40 at the time of admission and under 100.

The third criteria for inclusion in the sample is that the patient should be admitted to a hospital with at least 30 admissions for heart attack in our dataset. This criterion is imposed for the validity of the econometric results. In principle, this criterion introduces a problem of biased sampling, but because only few patients were thereby eliminated we believe that this is not a major problem. ${ }^{1}$

The fourth criterion is that the length of stay of each patient must be in the interval from one day to thirty days. Less than one day is considered as immediate transfer, and more than thirty days as a patient no longer in hospital for heart attack care.

\footnotetext{
${ }^{1}$ In the literature, hospitals having at least 30 AMI admissions in every year are considered as "high volume" (McClellan and Staiger (1999).
} 


\subsection{Variable construction}

We have three kinds of variables: demographic variables, indicators of disease severity and information about hospitals ${ }^{2}$.

The demographic variables are age, sex, a proxy for the distance ${ }^{3}$ between the domicile and the in-hospital and an indicator for inpatient death (called death).

Indicators of disease severity are constructed from the information on diagnosis codes contained in discharge records. We constructed nine diagnosis codes ${ }^{4}$. Moreover, we have information on the procedures carried out during the admission (catheterisation use, angioplasty, stent, surgery bypass) and an indicator for the surgical procedure used.

There are four kinds of hospital ownership: university hospitals called "main regional hospitals", local hospitals, not-for-profit hospitals and for-profit hospitals. Not-for-profit hospitals (called PSPH) are private but they are regulated as a public hospital and they cannot select patients.

\subsection{Initial evidence}

We see that on average, female patients are older then males (Table 1). We distinguish the distribution of inpatients by age and gender. This distribution is comparable between the for-profit and university hospitals (Graphs 1 and 2). The proportion of younger (up to 70) and male inpatients is much higher in these hospitals than in the others. Moreover, rates of specific secondary coronary diagnoses are lower in these hospitals (Graph 4). Both of these types of hospitals can perform intensive and innovative procedures. The medical literature (Regueiro et al., 2003 ; Rathore et al., 2003) is well documented on the fact that innovative procedures may only be used on patients with non-severe symptoms. This result

\footnotetext{
${ }^{2}$ In this dataset, we do not have inpatients admitted in emergencies.

${ }^{3}$ Prox is an indicator for the equality of the two district codes (the district of domicile and that admission of the hospital). When we estimated the different models, this variable was never significant. We thus decided to present the results without this variable.

${ }^{4}$ After estimations of different models, only a subset of these variables was kept for the estimations presented here.
} 
may seem surprising because older patients are generally in poorer health. Actually, this is due to the fact that they receive fewer prodecures. Therefore, it seems that the ability to carry out innovative procedures has an effect on the patient characteristic structure ${ }^{5}$.

We might suspect that the incentives to code diagnoses were greater for certain categories of hospital than for others. This does not seem to be the case (Graph 4). We observe neither an absence of secondary coronary diagnosis of patients for specific hospital types, nor a higher rate of every secondary coronary diagnosis for specific hospital ownership. Therefore, secondary diagnoses are not a bad indicator of illness severity: whatever the type, hospitals appear to have the same coding behaviour of coding.

Controlling by the ability to perform incentive and innovative procedure, the distribution of DRG assignment by hospital type is quite similar (Graph 5). These results tend to show that for-profit hospitals do not upcode DRGs. ${ }^{6}$

\subsection{Mortality and length of stay}

The general average length of stay is around 9 days for local public hospitals. It is about 2 days longer in not-for-profit hospitals and 1 day shorter in for-profit hospitals (graph 6). One interesting feature is that when the patient died during her/his stay, the average length of stay (with death) is between 5 and 6 days whatever the type of hospital. For both not-for-profit and for-profit hospitals, the average length of stay with discharge "return to home" is similar and greater than that for the two other hospital ownership types.

As explained in the introduction, the hospital quality ranking (given by the mortality rate) is completely dependant on the composition of patients (see Table 1 and Graph 7 ). Thus, for-profit hospitals have the lowest mortality rates over the whole sample but one of the highest mortality rates for the under 80 s.

\footnotetext{
${ }^{5}$ Milcent (2001) obtained the same result on the public sector.

${ }^{6}$ This is not what Silverman and Skinner (2001) found for pneumonia in the US. However, the reimbursement of French hospitals is not based on French DRGs yet.
} 
Illness severity explains the mortality rate. However, it is likely that unobserved heterogeneity within hospitals or within hospital types can explain part of the mortality rate. With an econometric approach, we can identify not only the effect of hospital ownership on mortality rate but also the variance within hospital ownership of this effect, i.e. the measurement of inefficiency heterogeneity within hospital type.

\subsection{Reimbursement system and innovation: Theoretical background}

There exist two types of reimbursement systems. Main regional hospitals, local hospitals and not-for-profit hospitals are paid by a global budget. They cannot make any profit. However, only main regional hospitals and local hospitals are defined as pertaining to the public sector. For-profit hospitals are regulated by fee-for-service. These hospitals have no constraint on profits. From Table 1, we see that, for this pathology, the majority of patients are admitted to public sector hospitals. Secondy, almost $50 \%$ of patients are admitted to local public hospitals.

\begin{tabular}{|l|l|l|}
\hline Indicator variables of hospital ownership & System of reimbursement & Sector \\
\hline Main regional (research, teaching, ...) & Global budget & Public \\
Local public & Global budget & Public \\
Not-for-profit & Global budget & Private \\
For-profit & Fee-for-service & Private \\
\hline
\end{tabular}

Financial incentives are quite different across sectors. Public sector hospitals are financed by a global budget and their doctors are salaried. One deterrent to public sector use of innovative procedures is the financing of supplies from a global budget, which makes it difficult to purchase expensive devices. The global budget system does not take costly procedures such as catheterization or angioplasty into account, and therefore penalises the innovative hospitals which use them. However, most private hospitals are financed via a 
fee-for-service system. Supplies such as stents are reimbursed ex-post in addition to the fee-for-service payment. Moreover, physicians receive additional fees for performing these procedures.

Hence, local public hospitals have the lowest rate of innovative procedures (Graph 3). As investment in innovative/complex procedures is one determinant of quality, this lower rate of innovative procedures could have an effect on the level of quality.

The rate of innovative procedures (catheterisation use, angioplasty, stent) is roughly similar for the public university hospitals and private sector hospitals (graph 3). These very few contrasted physician behaviours can be interpreted by the existence of many indirect financial or non-financial incentives for physicians working in the public sector. In university hospitals, physicians are involved in international competition for research. Their career depends partly on their success in scientific publication. In addition, the allocation of the budget also relies on the hospital's reputation. The result is that in the public as well as the private sector, some hospitals have the equipment to perform complex, expensive and/or innovative procedures.

Hospital ownership and remuneration structures are hence likely to generate variations in inputs that affect cost and quality through the different objectives and constraints that hospitals face. In this context, we sketch different strategies depending on hospital type. Public hospitals cannot select or discriminate amongst patients. Facing binding cost constraints, we suppose that, for a given level of innovation, the care quality offered by hospitals in the public sector is identical whatever the hospital. In the private sector, hospitals face both a payment and a cost function and they decide on care quality. We suppose that this level of quality depends on an exogenous factor that could be market share and the framework of this market (i.e. a function of the level of innovation of the hospitals in the public sector) or patient types which can be more or less remunerative, or both.

The first point is that, the hospital has the same level of care quality whatever the 
patient. So, patient characteristics will be independent of the level of care quality. However, the level of care quality depends on the hospital. So for this hospital type, we may observe some variation in this level.

The second point suggests that, the level of care quality depends on patient characteristics. Thereby, the average level of care quality in the hospital will depend on the hospital itself through the structure of its patient characteristics. We will test this assumption in the next section.

\section{Empirical specification}

\subsection{Why a duration model?}

Most studies in the literature have estimated separate regressions for the length of stay and inpatient mortality, hence assuming that these events are independent. The problem is that this can lead to misinterpretation. For example, in the following case: patients admitted to a private sector hospital have shorter lengths of stay, but this has no effect on in-hospital mortality conditional upon length of stay. A separate regression of mortality on hospital type may yield erroneous results. On the one hand, patients admitted to private hospitals stay less long; on the other hand, in-hospital deaths are less likely to be observed for patients with shorter lengths of stay when the outcomes are positively correlated. Thereby, we may obtain a significant effect whereas hospital type has no effect on in-hospital mortality (Hamilton and Hamilton, 1997; Ho et al., 2000b).

Some part of the literature on quality in health care and hospital behaviour accounts for this possible correlation by using the AMI mortality at various durations as the outcome variable (McClellan and Staiger, 2000b). In graph 6, we observe large differences in the duration of length of stay between hospital types. So, the drawbacks of this method appear clearly. For a given duration, if patients in hospital $A$ have shorter lengths of stay than 
patients in hospital $B$, then we will also be less likely to observe inpatient mortality among patients of hospital $A$. In this study, we use a duration model in order to take into account the possible correlation between mortality rate and length of stay (Hamilton and Hamilton, 1997). In this paper, these two dimensions of outcomes - duration and mortality- should not be studied separately. Therefore, the length of stay and discharge destination are estimated jointly using a duration model with multiple destinations ${ }^{7}$, called a competing risk model. In this way, we compute the probability that the patient is discharged to destination $r$ (death or home) after $m$ days in hospital, conditional on having survived in the hospital for at least $m$ days. We account for the observed and unobserved individual and hospital characteristics recorded at date $t$ when patient $i$ is admitted to hospital $h$ that are likely to impact on both the live discharge and the instantaneous probability of in-hospital mortality.

To facilitate comparisons with both the duration model used in this paper and across the wider literature, we propose to compare this model with a more conventional empirical framework. Therefore, in the next section we present the estimation of the AMI mortality rate as the dependant variable as well.

\subsection{A Proportional Hazard model}

In the Proportional Hazard $(\mathrm{PH})$ models, differences in independent variables imply a scaling of the common baseline survivor function. For the Accelerated Failure Time model, the effect of the covariates is to change the time scale by a constant (survival time-invariant) scale factor (Allison, 1995). To decide which method is the most appropriate, we use the Wilcoxon-Beslow test. The test statistic results imply a proportional relation. Thereby, we consider a PH model for this study.

\footnotetext{
${ }^{7}$ The types of discharge are return at home or death.
} 
Consider a PH model (Lancaster, 1990):

$$
h(t, X)=h_{0}(t) \exp \left(X^{\prime} \delta\right)
$$

where $t=$ time or time period; $h_{0}(t)=$ the baseline hazard function that summarizes the pattern of "duration dependence" common to all individuals; $\exp \left(X^{\prime} \delta\right)=$ a non-negative function of covariates $X$ composed of $W$ and $V$ such as

$$
X_{i}^{\prime} \delta=V_{i}^{\prime} \alpha+W_{h(i)}^{\prime} \gamma
$$

$i$ =the stay of the inpatient, $i \in\{1, \ldots, n\}$; and $h(i)=$ the hospital $h$ of inpatient $i$, $h \in\{1, \ldots, H\} . V$ are the observed variables of inpatient characteristics, sex, age, procedures received during the stay, and secondary diagnosis noted during the stay; $W$ are the observed variables of the hospital. In a first step ${ }^{8}$, we focus only on dummy variables for hospital ownership (university hospitals, local hospitals, not-for-profit hospitals, and for-profit hospitals).

In this model, we have multiple destinations: alive or dead. We use thus a right censoring model that can also be interpreted as a competing risks model. This way, we obtain the instantaneous probability of dying at time $t$ given that the patient is still living at time $t$.

\subsection{Unobserved individual heterogeneity}

We consider that the estimated model includes unobserved individual heterogeneity ${ }^{9}$. Thus, unobserved differences between observations are introduced via a multiplicative scaling factor, $v$. This unobserved heterogeneity parameter takes positive values, with the mean

\footnotetext{
${ }^{8}$ In the following, $W_{h(i)}$ corresponds to indicators for hospital ownership and indicators for technical hospitals, size and so on.

${ }^{9}$ In this paper, the unobserved individual heterogeneity is also called individual frailty.
} 
normalized to one (for identification reasons) and finite variance $\sigma^{2}$. We suppose that $v$ is distributed independently of $X$ and $t$. In principle, any continuous distribution with positive support, mean one and finite variance is a suitable candidate to represent the distribution of the random variable. Here, we use the two that are most common: the Gamma and Inverse Gaussian distributions.

The frailty hazard rate can be written,

$$
h(t \mid X, v)=h_{0}(t) \exp \left(X^{\prime} \delta\right) \cdot v=h_{0}(t) \exp \left(X^{\prime} \delta+u\right) \quad \text { with } u \equiv \ln (v)
$$

In this study we have no time varying covariates. Hence, the unobserved individual heterogeneity summarises both the impact of omitted variables on the hazard rate and errors of measurement in recorded regressors (Lancaster, 1990).

Because of the choice of pathology, the omitted variables that have an impact on the instantaneous probability of in-mortality are variables relating to the in-patient's health status. In this model, we take into account different variables giving information on the health status of the in-patient (age and secondary diagnosis). It is thus possible that we do not have omitted variables in the model. In this case, we will not observe any unobserved individual heterogeneity.

We suppose that the unobserved individual heterogeneity is not correlated with the observed independent variables.

\subsection{Unobserved hospital heterogeneity}

We now consider that the estimated model includes unobserved hospital heterogeneity noted $\varepsilon_{h(i)}$. Through this variable, we suppose that the unobserved inefficiency of hospitals explains part of the instantaneous mortality rate. 
Using equations (3) and (2), the frailty hazard rate can be written,

$$
h(t \mid W, V, u, \varepsilon)=h_{0}(t) \exp \left(V_{i}^{\prime} \alpha+W_{h(i)}^{\prime} \gamma+\varepsilon_{h(i)}+u_{i}\right)
$$

\subsection{Estimation in two steps}

The estimated model includes unobserved individual heterogeneity $u_{i}$ and unobserved hospital heterogeneity noted $\varepsilon_{h}$. Unobserved heterogeneity $u_{i}$ allows to control for differences in the composition of patients between hospitals. Through the variable $\varepsilon_{h}$, we assess the unobserved inefficency of hospital's. The issue is that we cannot identify both residuals $u_{i}$ and $\varepsilon_{h}$ directly from equation (4).

$$
\begin{aligned}
h(t \mid V, u) & =h_{0}(t) \exp \left(V_{i}^{\prime} \alpha+\beta_{h(i)}+u_{i}\right) \\
\beta_{h} & =W_{h}^{\prime} \gamma+\varepsilon_{h}
\end{aligned}
$$

In the first step, the hospital fixed effects $\beta_{h}$ are included in the specification (equation (5)). $\beta_{h}$ represents the degree hospital inefficiency in the quality provided. This way, we obtain a consistent estimator of $\beta_{h}$ : $\widehat{\beta_{h}}$. In a second step, we estimate equation (6) what allows to estimate of the observed and unobserved hospital heterogeneity.

However, a measurement error $\zeta_{h}$ is produced because we have $\widehat{\beta_{h}}$ and not $\beta_{h}$. So, we estimate,

$$
\widehat{\beta_{h}}=W_{h}^{\prime} \gamma+\varepsilon_{h}+\zeta_{h}
$$

Decomposing in two steps has two advantages. First of all, it allows us measure heterogeneity within hospital types: In a first step, we estimate hospital fixed effects. Therefore, we are able to measure the variance of the heterogeneity component by hospital type. Second, estimating hospital fixed effects in a first step allows us not to impose any parametric struc- 
ture on unobserved hospital heterogeneity $\varepsilon_{h}$ and to obtain two unobserved heterogeneity components in a duration model.

\subsection{Heterogeneity within hospital ownership}

One of the goals of this study is to measure the inefficiency heterogeneity within hospital types. From this equation (7), we now can obtain the inefficiency variance by hospital ownership, a measurement of the inefficiency heterogeneity within hospital type. A consistent estimator of the variance of $\gamma_{F G L S}$ is given by ${ }^{10}$ (Gobillon, 2002) :

$$
V(\gamma)_{F G L S}=\left[W^{\prime}(V(\varepsilon+\zeta))^{-1} W\right]^{-1}
$$

The method is explained in the Appendix.

\section{Findings}

The patient of reference is a male patient, aged 35, with no secondary diagnosis. In the following, the term "patient" will define the inpatient of reference.

\subsection{Estimation using Piece-wise Constant Exponential model}

All we need to estimate a PCE model is to generate variables which allow the constant term in the hazard regression to differ from interval to interval. In this study, we allow the baseline hazard to differ over eight intervals: first day, second day, third day, fourth day, from 4 to 8 days, from 8 to 15 days, from 15 to 22 days and, over 22 days. We call these dummies $t j$ with $j$ the number of the time interval. We choose the indicator corresponding to the interval from 4 to 8 days as the reference. Choosing a reference and including the other indicators as covariates in the exponential regression model allow us to

\footnotetext{
${ }^{10}$ FGLS: Feasible Generalized Least Squares.
} 
compare baseline hazard rates between intervals.

\subsubsection{Robustness}

To verify that the model is well specified, we compare the coefficients estimated by PCE (a more constrained model than Cox) with the coefficients obtained with the Cox PH model. Moreover, using a PCE model rather than a Cox model permites an easier introduction of an unobserved heterogeneity parameter (Horowitz, 1999).

In the appendix, table $2^{11}$, we present results obtained by using a Cox PH model (column (1)) and PCE (column (2)) without unobserved heterogeneity. The results obtained from the Cox PH model are very close to those obtained by PCE. So, we can conclude regarding the robustness of the model that the coefficients obtained seem consistent.

\subsubsection{Unobserved and observed individual heterogeneity}

In table 2, column (2), we consider only unobserved hospital heterogeneity. In column (3), we consider both unobserved individual and hospital heterogeneity. If we compare the results, we notice no major differences. In both models, the unobserved individual heterogeneity is insignificant at the $1 \%, 5 \%$ and $10 \%$ levels. So, we conclude that there is no parametric unobserved individual heterogeneity when we control for observed individual heterogeneity.

We compare the constant terms from interval to interval to the reference. We observe (Graph 8) that the baseline hazard rates are much higher for the first interval (one day) and the last interval (over 22 days).

The output shows that there is a positive association between age and the hazard rate: a one-year rise in age is associated with $7 \%$ higher probability of dying in hospital (Table 2).

\footnotetext{
${ }^{11}$ Models are estimated with age structure crossed with sex indicator variables, too. We chose to present results with just two variables (sex and age) because of the number of coefficients.
} 
This result is intuitive. Older patients are at greater risk of death after a heart attack. In the same way, we find that female patients have a higher probability of in-death. This last result echoes the literature in cardiology which shows that less procedures are performed on women and that they have a greater probability of in-death. Moreover, we observe that patients with more co-morbidities have greater probability of inpatient death.

\subsubsection{Identifying additional effects}

In our current formulation, the hazard model constrains the coefficients on the case-mix and baseline hazard variables to be independent of hospital type. As explained in section 2.5 , we can assume that differences in care quality, and subsequently outcomes, according to patient type may be observed for hospitals in the private sector. If this assumption holds, these coefficients should be independent of the hospital type. One way to test this is to estimate separate regressions for the four types of hospital.

The results presented in table $2 \mathrm{~b}$ show some differences in the significant estimated coefficients of the case-mix. However, these differences do not reveal differences in outcomes across the public and private sectors for patients with specific characteristics. In fact, the significant coefficients of the case-mix for hospitals in the private sector are similar to those for main regional hospitals or not-for-profit hospitals. These differences thus suggest different practices for main regional hospitals and private hospitals versus local hospitals.

Considering the estimated coefficients on the time dummies, we observe that they differ by hospital type. These coefficients may reflect hospitals' responses to unobserved patient types. We assume that hospitals' decisions to admit or treat a patient are based on the level of deterioration in patient health. We note that the coefficients of main regional hospitals and for-profit hospitals are not significantly different. Main regional hospitals are not able to select or to discriminate between patients, as for-profit hospitals can. So, if these differences are due to unobserved patient characteristics, they are not due to the level 
of health status severity. However, these differences can be due to the hospital's choice of patients. Patients with some characteristics such as being informed of the level of innovative procedures performed in the hospital, prefer to be admitted to specific hospital types. Our interpretation is based on the arguable assumption that these specific characteristics (such as a good knowledge of hospital reputations) are not correlated with the health state of the patient (in the case of heart attack). Hence, the estimation of the impact of hospital type controls for patient health heterogeneity.

\subsubsection{Hospitals ownership}

Hospital inefficiency parameters can be explained not only by hospital ownership but also by the fact that a hospital is able to perform innovative procedures. In this study, we work on heart attacks, hence the innovative procedure considered here is percutaneous transluminal coronary angioplasty ${ }^{12}$. We called this indicator PTCA. Furthermore, we suppose that the rate of innovative procedures can also be an independent variable that explains the inefficiency parameter. Another potential variable here is the unit care size of hospital. We use a proxy corresponding to the number of patients during the year.

The results are presented in Table 3, column 1. A local public hospital is a public firm. The manager and the staff are civil servants. A not-for-profit hospital is a private firm. The manager hires his staff as do private firms. However, both of them are paid by global budget. So, in comparing the inefficiency of these hospitals, we evaluate the effect of the hospital ownership for hospitals under the same system of reimbursement. We find that hospitals run by a private manager and civil servants do not have significantly different outcomes. Ownership does not appear to reflect efficiency differences. We obtain the same results by taking into account the ability to perform procedures, the rate of innovative procedure and/or the size of unit care (number of heart attack inpatients over the year).

\footnotetext{
${ }^{12} \mathrm{~A}$ cardiologist inserts a catheter with a deflated balloon at its tip into the artery.
} 
We now, evaluate the effect of the system of payment. Not-for-profit hospitals and forprofit hospitals are private firms. The formers are paid by global budget whereas the latter are paid by fee-for-service. The results shows that an admission to a for-profit hospital is associated with a lower conditional probability of death discharge from the hospital. Therefore, fee-for-service reimbursement is associated with greater hospital efficiency than reimbursement by global budget. The difference in hospital efficiency is not significant at the level of $5 \%$ when we account for the ability to perform innovative procedures, the innovative procedure rate and/or the size of hospital care unit (Table 3, column 1).

Local public hospitals and university hospitals are financed by global budgets. Furthermore, these hospitals are public firms. Nevertheless, we can distinguish them by their status. On the one hand, local hospitals are hospitals with little or medium size care units, they are numerous and they are dispersed widely throughout the territory. On the other hand, each French region only has between one and two university hospitals. So inefficiency differences reflect the effect of assignment on efficiency. We observe no significant difference between hospital inefficiency whatever the independent variables of the model (Table 3, column 4).

The hospital's ability to perform complex or innovative procedures and the innovative procedure rate is highly correlated with hospital ownership. Thereby, controling the inefficiency parameter by the hospital ownership, it appears that the hospital's ability to perform complex or innovative procedure is not significant (Table 3).

Taking into account the observed patient characteristic structure (age and gender) does not change the effect of reimbursement type and ownership. 


\subsection{Variance analysis}

\subsubsection{Variation within hospital types}

We find that hospital ownership explains only $3.4 \%$ of the total variance. We saw that the inefficiency parameter can be explained not only by hospital ownership but also by the hospital's ability to perform innovative procedures, the rate of innovative procedure and care unit size. By taking into account these independent variables, the share of explained variance is $4 \%$.

Moreover, if gender is not significant, the age of inpatient has a positive effect on quality inefficency. However, the share of explained variance is still very low (Table 2, column 5).

These results raise another question: what are the other determinants of hospital heterogeneity? First of all, we could suggest staff variation. Whatever the hospital type, some variation in staff structure may explain these differences. In addition, geographical variables such as urban versus rural, or socio-economic variables could have an effect. Returns to scale may also play a role whatever hospital types, some hospitals may have better management than others. Moreover, the level of specialisation can differ depending on the hospitals and, this may explain part of hospital heterogeneity.

\subsubsection{The inpatient death rate and the composition of patients by age and $\operatorname{sex}$}

The composition of patients by age and sex varies according to the hospital. Therefore, to evaluate the consistency of the hospital ranking by inpatient death rate, we compute the share of variance explained by age and sex (see Table 4 ). We find that $51 \%$ of inpatient death rate variance is explained by patients' age and sex. This result raises the issue of the consistency of the hospital ranking by inpatient death rate. 


\subsubsection{Variance within hospital ownerships}

We consider the variance of heterogeneity between hospitals, by hospital ownership (Table 5). These variances are computed as described in the section (3.6).

First of all, the variance within hospital ownership does not depend on the hospital's ability to perform complex or/and innovative procedures. Secondly, hospital heterogeneity variance depends strongly on hospital ownership. The standard deviation is twenty times larger for for-profit hospitals than for government hospitals. Another element is the homogeneity of quality level ${ }^{13}$ for not-for-profit hospitals. These results are unchanged when we account for the hospital's ability to perform innovative procedures, the rate of innovative procedure and care unit size.

\section{Conclusion}

The ranking of hospitals by mortality rate can be totally biased by the composition of inpatients. Statistical results show that, over the whole sample, for profit hospitals have the lowest mortality rates but, for male patients aged between 50 and 60 , the highest mortality rate. These results are due to the fact that patients who receive innovative or complex procedures are directed to hospitals that are able to perform them.

We thus use a duration model with multiple destinations which accounts for both observed and unobserved (by the researcher) variables. The originality of this study is that we consider unobserved inpatient heterogeneity and unobserved hospital heterogeneity. We thus propose a duration model with two types of residuals. Moreover, no distributional assumptions are made regarding the unobserved hospital heterogeneity residuals.

Heterogeneity between for-profit hospitals is greater than between university hospitals (the variance of the estimated coefficients is almost four hundred times larger). These

\footnotetext{
${ }^{13}$ The quality level is measured by the conditional probability of in-death.
} 
results suggest that being admitted into a for-profit hospital has two consequences: a lower risk of death, and greater uncertainty about the quality of the hospital, with quality measured in terms of the instantaneous probability of death. This also raises a question: what does quality measure? The average quality level? The variance of this quality level? Current, standards like the ISO 9002 define a product by the homogeneity of the level of quality. Should we use the same concept for hospitals?

Hospitals in the public sector are more homogeneous than those in the private sector. These results suggest that increasing the ability to adopt innovative procedures would increase the quality of care by ensuring a homogeneity in the quality of care provided by these hospitals. In setting up the budget constraint, the regulator has to bear in mind that it may have consequences on the ability of the public sector to perform innovative procedures and thus on the quality of care.

One key result in the literature is that the ranking of hospitals can be extremely sensitive to unobserved differences in the case-mix of patients. In the context of time series data, McClellan and Staiger (1999) and Propper et al. (2003) suggest two ways of overcoming this problem. However, McClellan and Staiger (1999) show that measures which use much more detailed medical data to account for differences in patient disease severity and comorbidity, which we have, lead to quite similar predictions.

Moreover, we resolve the issue of differences in patient characteristic structure by taking into account observed and unobserved patient characteristics, and the observed patient characteristic structure in hospitals. Nevertheless, it is possible that the estimated hospitalspecific effects depend on the response of hospitals to unobserved patient characteristics.

In this paper, few observable hospital characteristics are used to explain the variation in hospital-specific effects. In the introduction and in the theoretical section, we refer to competition between hospitals as being one of the few variables that generates significant 
differences in quality between ownership forms. It would be interesting to study the link between competition and quality in French hospitals.

In this study, we have adopted a parametric approach for the residual, although a non parametric approach as suggested by Heckman and Singer (1984) could be also used.

We considered that the patient characteristic structure reflects the needs of patients to receive more complex or innovative procedures. However, it can also be due to patients' choice for some kind of hospitals. Socio-economic information on patients would allow us to model the choice of the patient (for a hospital or/and a hospital type).

The investment in innovative procedures differs according to the system of reimbursement. Hospitals in the private sector may benefit by performing innovative procedures and hospitals of the public sector do not. So, if innovative procedures have an impact on the long-term mortality rate, so could the system of reimbursement. To answer this question, we would need to have longitudinal data on the survival of patients.

\section{References}

Allison, J.J., Kiefe, C.I., Weissman N.W. (2000) "Relationship of Hospital Teaching Status with Quality of Care and Mortality for Patients with Acute MI" J ournal of American Medical Association, 284, 1256-1262.

Allison, P. (1995) Survival Analysis Using SA S System: A Practical Guide, SAS Institute, Gary NC.

Arrow, K.J. (1963) "Uncertainty and the Welfare Economics of Medical Care", American Economic Review, 53, 941-973.

Cutler, D.M., Horwitz, J.R. (1998). Converting Hospitals from Not-for-Profit to ForProfit States: Why and What Effects? National Bureau of Economic Research Working Paper No. 6672. 
Dubois R.W., Rogers W.H., Moxley J.H., Draper D., and Brook R.H. "Hospital inpatient mortality. Is it a predictor of quality?" the New England J ournal of M edecine, 317 (26), 1674-1680.

Geweke, J, Gowrisankaran, G., and Town, R. (2003) "Inferring Hospital Quality from Patient Discharge Records Using a Bayesian Selection Model," Econometrica, forthcoming.

Gobillon, L. (2002) "Mobilité résidentielle et marchés locaux de l'emploi", Ph.D. dissertation, EHESS Paris.

Goworisakaran G. and Town R. (1999) "Estimating quality of Care in Hospitals Using Instrumental Variables", J ournal of Health Economics, 18, 747-67.

Goworisakaran G. and Town R. (2002) "Competition, Payers, and Hospital Quality", NBER working paper

Hamilton and Hamilton V. (1997) "Estimating surgical volume-outcome relationships applying survival models: accounting for frailty and hospital fixed effects", Health Economics, 6, 383-395.

Hansman, H.B. (1996) The ownership of Enterprise, Cambridge, Mass.: Havard University Press.

Hartz A.J., Krakauer H., Kuhn E.M. (1989) "Hospital Characteristics and Mortality Rates". New England J ournal of M edecine, 321, 1720-1725.

Heckman, J. and Singer, B. (1984) "A method for minimizing the impact of distributional asumptions in econometrics models for duration data", Econometrica, 52, 271-320.

Ho, V. (2002) "Learning and the evolution of medical technologies: the diffusion of coronary angioplasty", J ournal of Health E conomics, 21, 373-885.

Ho V. and Hamilton B. (2000a) "Hospital mergers and acquisitions: Does market consolidation harm patients?" J ournal of Health E conomics, 19(5), 767-791.

Ho V. Hamilton B. and Roos, L. (2000b) "Multiple Approches to Assessing the Effects of Delays for Hip Fracture Patients in the United States and Canada", Health Services 
Research.

Kessler D. and McClellan M. (2000) "Is hospital competition socially wasteful?", Quaterly J ournal of E conomics, 115(2), 577-615.

Kessler D. and McClellan M. (2002) "The effects of hospital ownership on medical productivity", RAND J ournal of Economics, 33 (3), 488-506.

Lancaster, T. (1990), The Econometric Analysis of Transition Data, Cambridge University Press.

McClellan M. and Staiger D. (1999) "The Quality of Health Care Providers", NBER Working Paper, $\mathrm{N}^{\circ} 7327$.

McClellan M. and Staiger D.O. (2000a) "Comparing Hospital Quality at For-Profit and Not-for-Profit Hospitals". In D.M. Cutler, ed., The Changing Hospital Industry: Comparing N ot-for-P rofit and For-P rofit Institutions. Chicago: University of Chicago Press, 2000.

McClellan and Staiger D.O. (2000b) "Comparing the quality of health care providers". In A. M. Garber, ed., Frontier in Health Policy Research. MIT Press, Cambridge, MA, Chapter 5 .

Milcent, C. (2001) "Tarification par pathologie, hétérogénéité des hôpitaux et innovations techniques" Ph.D. dissertation, Université Paris X.

Newhouse, J. (1970) "Toward a Theory of Nonprofit Institutions". A merican Economic Review, 60 (1)64-74.

Pauly M.V. and Redish M. (1973) "The Not-for-Profit Hospital as a Physicians' cooperative", American E conomic Review, 63, 87-99.

Picone G., Shin-Yi C., and Sloan, F. (2002) "Are for-profit hospital conversions harmful to patients and to Medicare ?", RAND J ournal of Economics, 33 (3), 507-523.

Propper, C. and Burgess S. and Green K. (2002) "Does competition between hospitals improve the quality of care? Hospital death rate and the NHS internal market", mimeo.

Propper, C. and Burgess S. and Gossage, D. (2003) "Competition and quality: Evidence 
from the NHS internal market 1991-1999", Technical report, CMPO.

Regueiro CR, Gill N, Hart A, Crawshaw L, Hentosz T, Shannon RP. Primary angioplasty in acute myocardial infarction: does age or race matter? J Thromb Thrombolysis. 2003 15(2):119-23.

Rathore SS, Mehta RH, Wang Y, Radford MJ, Krumholz HM.Effects of age on the quality of care provided to older patients with acute myocardial infarction. Am J Med. 2003 114(4):307-15.

Silverman E.M.and Skinner J.S. (2001) "Are For-Profit Hospitals Really different? Medicare Upcoding and Market Structure", NBER working paper.

Shortell S.M. and Highes E.F.X. (1998) "The effects of Regulation, Competition, and Ownership on Mortality Rates Among Hospital Inpatients", New England J ournal of M edecine, 318, 1100-1107.

Sloan F. , Picone G., Taylor D. and Chou S. (1999), "Hospital Ownership and Cost and Quality of Care: Is There a Dime's Worth of Difference?", W orking Paper.

Wray N. J., Hollinghsworth, N. Petersen, and C. Ashton (1997), "Case-Mix Adjustement Using Administrative Databases: A Paradigm to Guide Future Research", Medical Care Research and Review, 54, 326-356.

\section{Appendix}

From the equation $\widehat{\beta_{h}}=W_{h}^{\prime} \gamma+\varepsilon_{h}+\zeta_{h}$, we can obtain the inefficiency variance by hospital ownership, a measurement of the inefficiency heterogeneity within hospital type.

In vector form, the equation $\widehat{\beta_{h}}=W_{h}^{\prime} \gamma+\varepsilon_{h}+\zeta_{h}$ can be written as

$$
\widehat{\beta}=W^{\prime} \gamma+\varepsilon+\zeta
$$


with $\beta=\left(\beta_{1}, \ldots, \beta_{H}\right), \varepsilon=\left(\varepsilon_{1}, \ldots, \varepsilon_{H}\right), \zeta=\left(\zeta_{1}, \ldots, \zeta_{H}\right)$ and

$$
\zeta_{h}=\widehat{\beta_{h}}-\beta_{h}
$$

From equation (8), we estimate $\gamma$ by ordinary least squares (OLS),

$$
\succ_{M C O}=\left(W^{\prime} W\right)^{-1} W^{\prime} \widehat{\beta}=\gamma+\left(W^{\prime} W\right)^{-1} W^{\prime}(\varepsilon+\zeta)
$$

By estimating model (8) by OLS, we have a heteroskedasticity problem. To resolve this issue, we need an unbiased and consistent estimator of the variance-covariance matrix $V(\varepsilon+\zeta)$

Under the assumptions,

$$
\begin{aligned}
& \operatorname{corr}(\varepsilon, \zeta)=0 \\
& \text { and } V(\varepsilon)=\sigma^{2} I
\end{aligned}
$$

we have,

$$
V(\varepsilon+\zeta)=\widehat{\sigma^{2}} I+\hat{V}(\zeta)
$$

an unbiased and consistent estimator $\widehat{\sigma^{2}}$ of $\sigma^{2}$ is (see Gobillon, 2002),

$$
\sigma^{2}=\frac{1}{\operatorname{tr}\left(M_{W}\right)}\left[(\varepsilon+\zeta)^{\prime}(\varepsilon+\zeta)-\operatorname{tr}\left[M_{W} \hat{V}(\zeta)\right]\right]
$$

with,

$$
\begin{aligned}
M_{W} & =I-W\left(W^{\prime} W\right)^{-1} W^{\prime} \\
(\downarrow+\zeta) & =\widehat{\beta}-W \rtimes_{M C O} \\
V(\zeta) & =V(\widehat{\beta}-\beta)=V(\widehat{\beta})
\end{aligned}
$$


and with $\hat{V}(\zeta)$ being the asymptotic estimator of the variance-covariance matrix obtained from of the first step estimators.

Therefore, from (9), an consistent estimator of the variance of $\gamma_{F G L S}$ is given by ${ }^{14}$ (Gobillon, 2002) :

$$
V(\gamma)_{F G L S}=\left[W^{\prime}(V(\varepsilon+\zeta))^{-1} W\right]^{-1}
$$

${ }^{14}$ FGLS: Feasible Generalized Least Squares. 
Table 1: descriptive statistics

\begin{tabular}{|l|cccc||c|}
\hline & $\begin{array}{l}\text { Main } \\
\text { regional } \\
\text { hospital }\end{array}$ & $\begin{array}{l}\text { Local } \\
\text { public }\end{array}$ & $\begin{array}{l}\text { Not-for- } \\
\text { profit }\end{array}$ & For-profit & All hospital \\
\hline $\begin{array}{l}\text { Number of } \\
\text { hospital }\end{array}$ & 31 & 169 & 23 & 64 & 287 \\
\hline $\begin{array}{l}\text { Number of } \\
\text { patients }\end{array}$ & 9,433 & 12,725 & 1,535 & 4,717 & 28,410 \\
\hline \% of women & $\begin{array}{c}26.1 \\
(0.43) *\end{array}$ & $\begin{array}{c}35.1 \\
(0.48)\end{array}$ & $\begin{array}{c}30.6 \\
(0.46)\end{array}$ & $24.5(0.43)$ & $\begin{array}{c}30.3 \\
(0.46)\end{array}$ \\
\hline $\begin{array}{l}\text { Average } \\
\text { patient age }\end{array}$ & $\begin{array}{c}65.5 \\
(13.52)\end{array}$ & $\begin{array}{c}70.7 \\
(13.48)\end{array}$ & $\begin{array}{c}68.7 \\
(13.37)\end{array}$ & $\begin{array}{c}65.4 \\
(12.50)\end{array}$ & $\begin{array}{c}68.0 \\
(13.58)\end{array}$ \\
\hline Mortality rate & $\begin{array}{c}9.4 \\
(0.29)\end{array}$ & $\begin{array}{c}14.6 \\
(0.35)\end{array}$ & $\begin{array}{c}10.0 \\
(0.29)\end{array}$ & $\begin{array}{c}6.4 \\
(0.24)\end{array}$ & $\begin{array}{c}11.3 \\
(0.32)\end{array}$ \\
\hline
\end{tabular}

*: standard deviation in parentheses

PMSI Database: 28,410 stays and 287 hospitals, 1997

Graph 1:

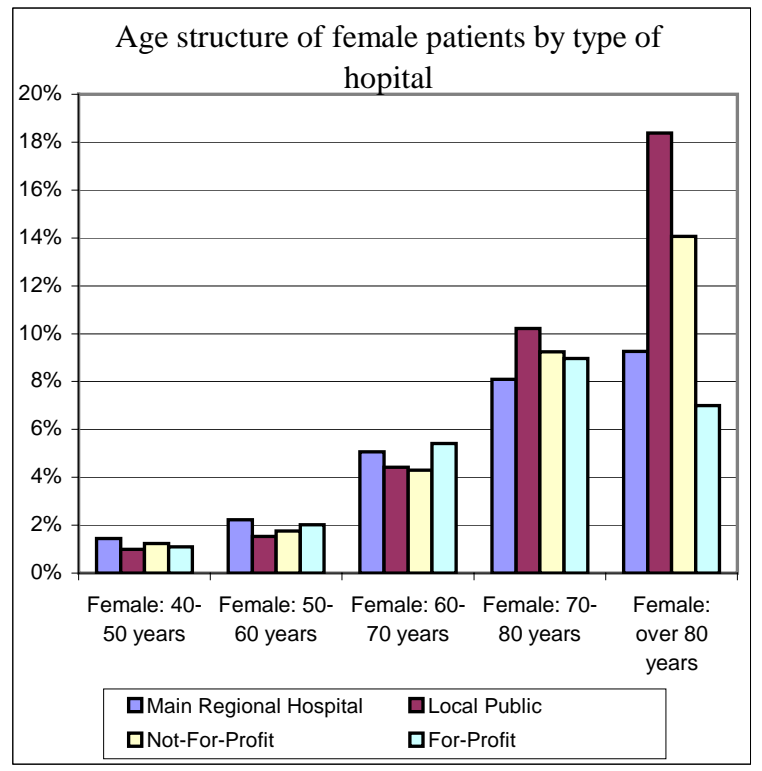

Graph 2:

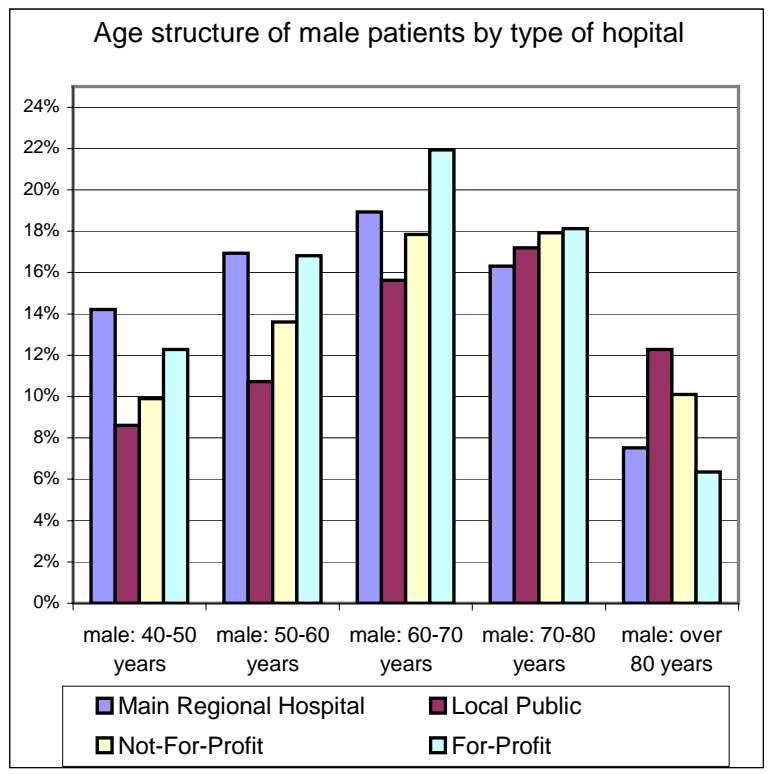

Graph 3:

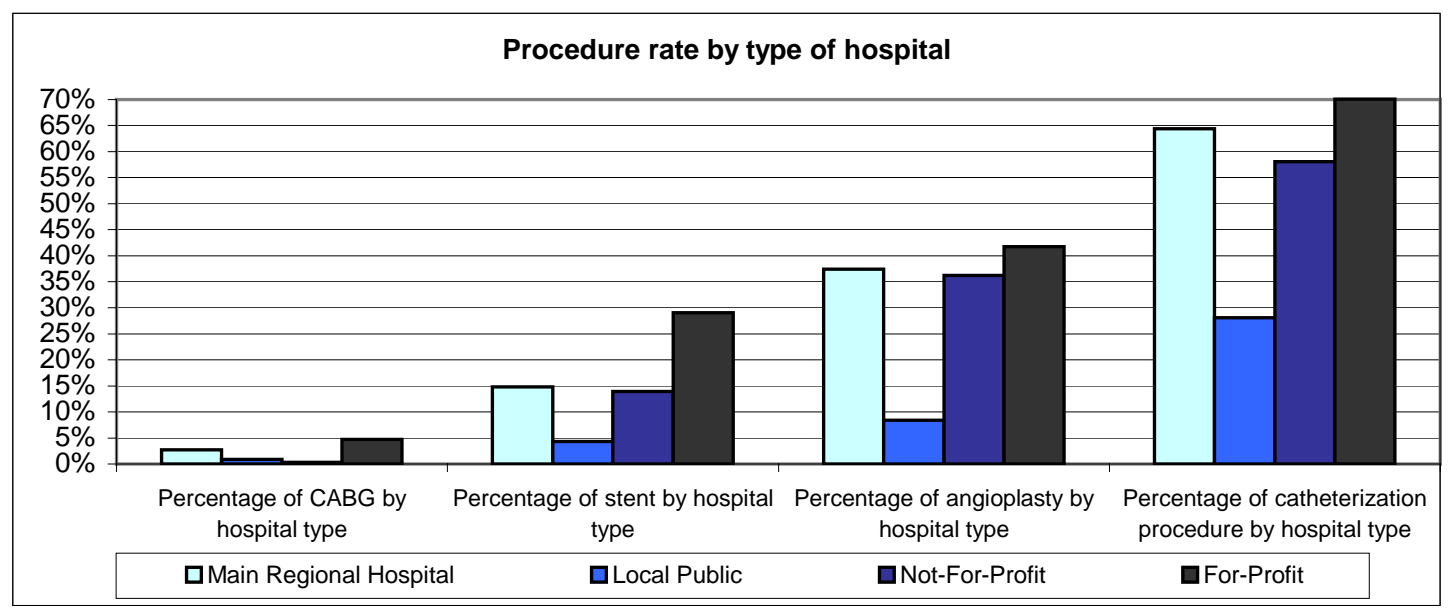


Graph 4:

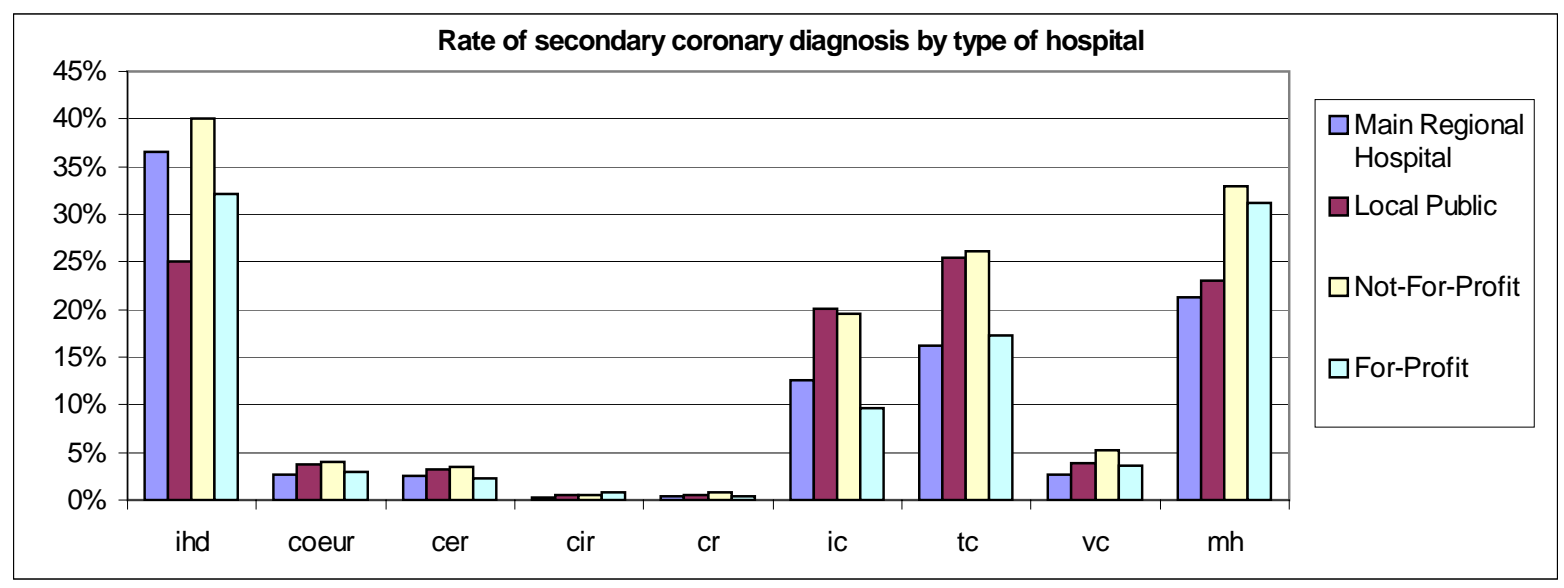

Graph 5:

Graph 6:
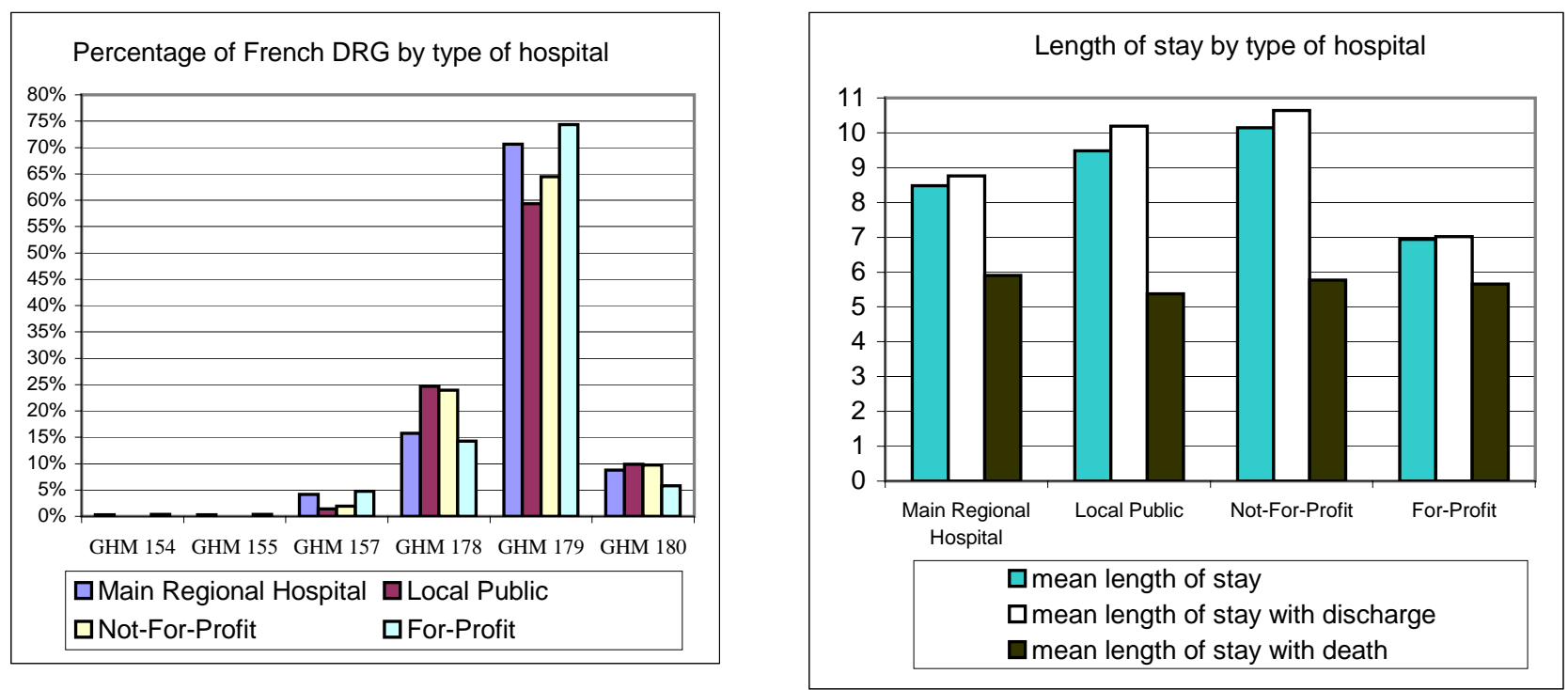

\section{Graph 7:}

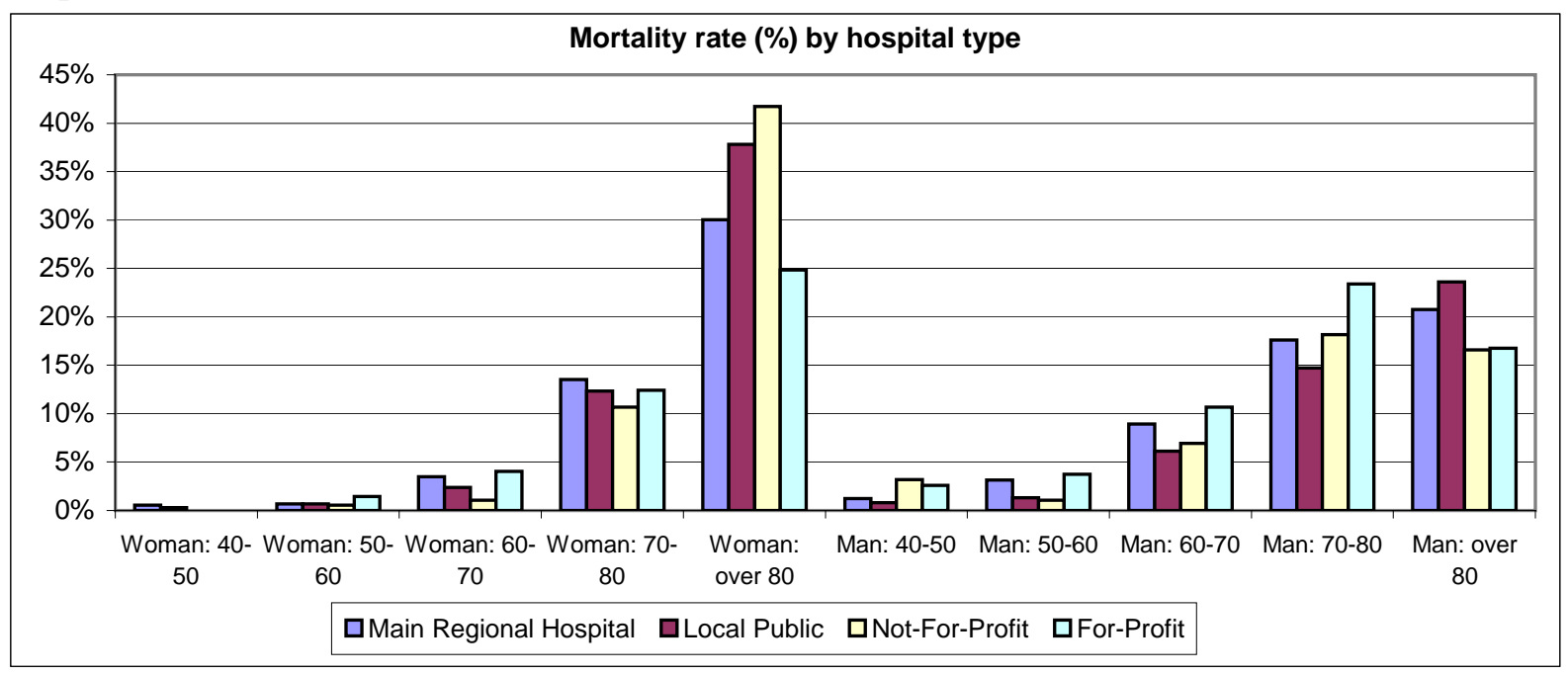


Table 2:

\begin{tabular}{|c|c|c|c|}
\hline & $\mathrm{PH} \operatorname{Cox}(1)$ & \begin{tabular}{|l|} 
PCE without \\
heterogeneity (2)
\end{tabular} & $\begin{array}{l}\text { PCE with } \\
\text { heterogeneity (2) }\end{array}$ \\
\hline \multicolumn{4}{|l|}{ Patient characteristics } \\
\hline \multirow[t]{2}{*}{ Age } & $0.066^{\star \star \star}$ & $0.066^{\star \star *}$ & $0.066^{\star \star \star}$ \\
\hline & {$[0.002]$} & {$[0.002]$} & {$[0.002]$} \\
\hline \multirow[t]{2}{*}{ Female } & $0.179 \star \star \star$ & $0.179 * \star \star$ & $0.179 \star * \star$ \\
\hline & {$[0.038]$} & {$[0.038]$} & {$[0.038]$} \\
\hline \multicolumn{4}{|l|}{ Severity disease } \\
\hline \multirow[t]{2}{*}{ Number of secondary diagnostic } & $0.049 * \star \star$ & $0.049 * \star \star$ & $0.049 \star \star \star$ \\
\hline & {$[0.014]$} & {$[0.014]$} & {$[0.014]$} \\
\hline \multirow[t]{2}{*}{ Surgical French DRGs } & $0.636^{\star \star \star}$ & $0.638^{\star \star \star}$ & $0.638^{\star \star \star}$ \\
\hline & {$[0.115]$} & {$[0.115]$} & {$[0.115]$} \\
\hline \multirow[t]{2}{*}{ ind } & $-0.154^{\star \star \star}$ & $-0.154^{\star \star \star}$ & $-0.154^{\star \star \star}$ \\
\hline & {$[0.036]$} & {$[0.036]$} & {$[0.036]$} \\
\hline \multirow[t]{2}{*}{ coeur } & $-0,123$ & $-0,123$ & $-0,123$ \\
\hline & {$[0.090]$} & {$[0.090]$} & {$[0.090]$} \\
\hline \multirow[t]{2}{*}{ cer } & $0.405^{\star \star \star}$ & $0.407^{\star \star \star}$ & $0.407^{\star \star \star}$ \\
\hline & {$[0.067]$} & {$[0.067]$} & {$[0.067]$} \\
\hline \multirow[t]{2}{*}{ cir } & $-0.634^{\star \star}$ & $-0.635^{\star \star}$ & $-0.635^{\star \star}$ \\
\hline & {$[0.305]$} & {$[0.304]$} & {$[0.305]$} \\
\hline \multirow[t]{2}{*}{ cr } & $-0,094$ & $-0,095$ & $-0,095$ \\
\hline & {$[0.201]$} & {$[0.201]$} & {$[0.201]$} \\
\hline \multirow[t]{2}{*}{ ic } & $0.198^{\star \star \star}$ & $0.199 * \star \star$ & $0.199 \star \star \star$ \\
\hline & {$[0.039]$} & {$[0.039]$} & {$[0.039]$} \\
\hline \multicolumn{4}{|l|}{ Interval } \\
\hline \multirow[t]{2}{*}{ interval= first day } & & 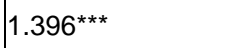 & $1.397^{\star \star \star}$ \\
\hline & & {$[0.059]$} & {$[0.059]$} \\
\hline \multirow[t]{2}{*}{ interval= second day } & & $0.812^{\star \star \star}$ & $0.812^{\star \star \star}$ \\
\hline & & {$[0.068]$} & {$[0.068]$} \\
\hline \multirow[t]{2}{*}{ interval=third day } & & $0.632^{\star \star \star}$ & $0.632^{\star \star \star}$ \\
\hline & & {$[0.073]$} & {$[0.073]$} \\
\hline \multirow[t]{2}{*}{ interval=fourth day } & & $0.459 * \star \star$ & 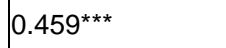 \\
\hline & & {$[0.078]$} & {$[0.078]$} \\
\hline \multirow[t]{2}{*}{ interval=from 4 to 8 days } & & $0.205^{\star \star \star}$ & $0.205^{\star \star \star}$ \\
\hline & & {$[0.061]$} & {$[0.061]$} \\
\hline interval=from 8 to 15 days & & Reference & Reference \\
\hline \multirow[t]{2}{*}{ interval=from 15 to 22 days } & & $0.433^{\star \star \star}$ & $0.433^{\star \star \star}$ \\
\hline & & {$[0.091]$} & {$[0.091]$} \\
\hline \multirow[t]{2}{*}{ interval= over 22 days } & & $1.074^{\star \star \star}$ & $1.074^{\star \star \star}$ \\
\hline & & {$[0.137]$} & {$[0.137]$} \\
\hline \multirow[t]{3}{*}{ Constant } & & $-9.965^{\star \star \star}$ & $-9.965^{\star \star \star}$ \\
\hline & & {$[0.175]$} & {$[0.175]$} \\
\hline & & & (b) \\
\hline \multirow[t]{2}{*}{ Variance of Gamma parameter } & & & 7.72e-07 \\
\hline & & & {$[0.0001451]$} \\
\hline \multicolumn{4}{|c|}{ Hospital fixed effects have been estimated but are not shown for presentational reasons } \\
\hline log likelihood & $-29690,63$ & $-11295,02$ & $-11295,02$ \\
\hline
\end{tabular}

Standard errors in brackets

* significant at 10\%; ** significant at 5\%; *** significant at $1 \%$

(b): Likelihood ratio test of theta $=0$ : chibar2(01) $=3.6 \mathrm{e}-05$ Prob $>=$ chibar2 $=0.498$

PMSI Database: 28,410 stays and 287 hospitals, 1997 
Table 2b:

\begin{tabular}{|c|c|c|c|c|}
\hline PCE with heterogeneity & Main regional hospital & Local public hospital & Not-For-Profit hospital & For-Profit hospital \\
\hline \multicolumn{5}{|l|}{ Patient characteristics } \\
\hline \multirow[t]{2}{*}{ Age } & $0.071 * * *$ & $0.065 * * *$ & $0.069 * * *$ & $0.057 * * *$ \\
\hline & {$[0.004]$} & {$[0.003]$} & {$[0.009]$} & {$[0.006]$} \\
\hline \multirow[t]{2}{*}{ Female } & $0.216 * * *$ & $0.129 * * *$ & 0.28 & 0.148 \\
\hline & {$[0.075]$} & [0.049] & {$[0.173]$} & {$[0.127]$} \\
\hline \multicolumn{5}{|l|}{ Severity disease } \\
\hline \multirow[t]{2}{*}{ Number of secondary diagnostic } & $0.093 * * *$ & $0.073^{*}$ & $0.063 * *$ & $0.089 * *$ \\
\hline & {$[0.024]$} & {$[0.037]$} & {$[0.031]$} & {$[0.042]$} \\
\hline \multirow[t]{2}{*}{ ind } & $-0.147 * *$ & $-0.111^{* *}$ & 0.112 & 0.042 \\
\hline & {$[0.059]$} & {$[0.044]$} & {$[0.125]$} & {$[0.096]$} \\
\hline \multirow[t]{2}{*}{ coeur } & 0.121 & -0.122 & -0.371 & -0.048 \\
\hline & {$[0.172]$} & {$[0.113]$} & {$[0.431]$} & {$[0.251]$} \\
\hline \multirow[t]{2}{*}{ cer } & $0.469 * * *$ & $0.528 * * *$ & $0.588 * *$ & $0.428 * *$ \\
\hline & {$[0.122]$} & {$[0.082]$} & {$[0.294]$} & {$[0.152]$} \\
\hline \multirow[t]{2}{*}{ cir } & -1.503 & $-0.737 *$ & 1.067 & -0.318 \\
\hline & [0.999] & {$[0.410]$} & {$[0.731]$} & {$[0.710]$} \\
\hline \multirow[t]{2}{*}{$\mathrm{cr}$} & 0.295 & $-0.668 *$ & $0.779 * *$ & $1.015^{* *}$ \\
\hline & {$[0.271]$} & {$[0.390]$} & {$[0.302]$} & {$[0.417]$} \\
\hline \multirow[t]{2}{*}{ ic } & $0.914 * * *$ & $0.088^{*}$ & $0.333^{* *}$ & $0.928 * * *$ \\
\hline & {$[0.068]$} & {$[0.046]$} & {$[0.164]$} & {$[0.127]$} \\
\hline \multicolumn{5}{|l|}{ Interval } \\
\hline \multirow[t]{2}{*}{ interval= first day } & $1.293 * * *$ & $1.531 * * *$ & $1.410 * * *$ & $0.878 * * *$ \\
\hline & {$[0.121]$} & {$[0.077]$} & {$[0.281]$} & {$[0.196]$} \\
\hline \multirow[t]{2}{*}{ interval= second day } & $0.650 * * *$ & $0.923 * * *$ & $1.082 * * *$ & $0.440 * *$ \\
\hline & {$[0.136]$} & [0.089] & {$[0.305]$} & {$[0.219]$} \\
\hline \multirow[t]{2}{*}{ interval=third day } & $0.429 * * *$ & $0.773 * * *$ & 0.435 & $0.385^{*}$ \\
\hline & {$[0.147]$} & {$[0.094]$} & {$[0.372]$} & {$[0.230]$} \\
\hline \multirow[t]{2}{*}{ interval=fourth day } & 0.259 & $0.592 * * *$ & 0.551 & 0.12 \\
\hline & {$[0.157]$} & {$[0.101]$} & {$[0.362]$} & {$[0.255]$} \\
\hline \multirow[t]{2}{*}{ interval=from 4 to 8 days } & 0.089 & $0.230 * * *$ & $0.659 * *$ & 0.051 \\
\hline & [0.119] & {$[0.080]$} & {$[0.264]$} & [0.195] \\
\hline interval=from 8 to 15 days & Reference & Reference & Reference & Reference \\
\hline \multirow[t]{2}{*}{ interval=from 15 to 22 days } & $0.537 * * *$ & $0.375^{* * *}$ & 0.234 & 0.424 \\
\hline & {$[0.193]$} & {$[0.124]$} & {$[0.416]$} & {$[0.294]$} \\
\hline \multirow[t]{2}{*}{ interval= over 22 days } & $1.402 * * *$ & $1.111^{* * *}$ & -0.663 & $1.067 * *$ \\
\hline & {$[0.513]$} & {$[0.183]$} & {$[1.024]$} & {$[0.437]$} \\
\hline \multirow[t]{2}{*}{ Constant } & $-10.248 * * *$ & $-9.794 * * *$ & $-10.593 * * *$ & $-9.358 * * *$ \\
\hline & {$[0.289]$} & {$[0.205]$} & {$[0.717]$} & {$[0.460]$} \\
\hline Log likelihood & -3230.24 & -6532.87 & -573.68 & -1192 \\
\hline
\end{tabular}

Standard errors in brackets

* significant at 10\%; ** significant at 5\%; *** significant at $1 \%$

PMSI Database: 28,410 stays and 287 hospitals, 1997 
Table 2c:

\begin{tabular}{|c|c|}
\hline & $\begin{array}{c}\text { Two step model: } \\
\text { First step, a Fixed effects Probit } \\
\text { Model, second step, an OLS model }\end{array}$ \\
\hline \multicolumn{2}{|l|}{ Hospital Types } \\
\hline \multirow[t]{2}{*}{ Main Regional Hospital } & 0,276 \\
\hline & {$[0,258]$} \\
\hline \multirow[t]{2}{*}{ Local Public Hospital } & 0,099 \\
\hline & {$[0,206]$} \\
\hline Not-For-Profit Hospital & Reference \\
\hline \multirow[t]{2}{*}{ For-Profit Hospital } & $-0,327^{\star *}$ \\
\hline & {$[0,155]$} \\
\hline \multirow[t]{2}{*}{ Constant } & $-5,919 * * *$ \\
\hline & {$[0,193]$} \\
\hline
\end{tabular}

Standard errors in brackets, computed by bootstrap

* significant at 10\%; ** significant at 5\%; *** significant at $1 \%$

PMSI Database: 28,410 stays and 287 hospitals, 1997

The literature on quality in health care and the behaviour of hospitals under different forms uses AMI mortality as the outcome variable. In contrast, this paper estimates a hazard function to account for the correlation between the length of stay and the mortality rate. Nevertheless, It could be helpful to estimate the model within a more conventional empirical framework. This would facilitate comparisons with both the duration model used in this paper and across the wider literature. To do so, we run a fixed effects Probit model. The results suggest the hospital-specific effects are significantly (at 5\%) lower in for-profit hospitals compared with not-for-profit and university hospitals. So, without taking into account the correlation between mortality rate and length of stay, the main result of this paper is found. 


\section{Graph 8:}

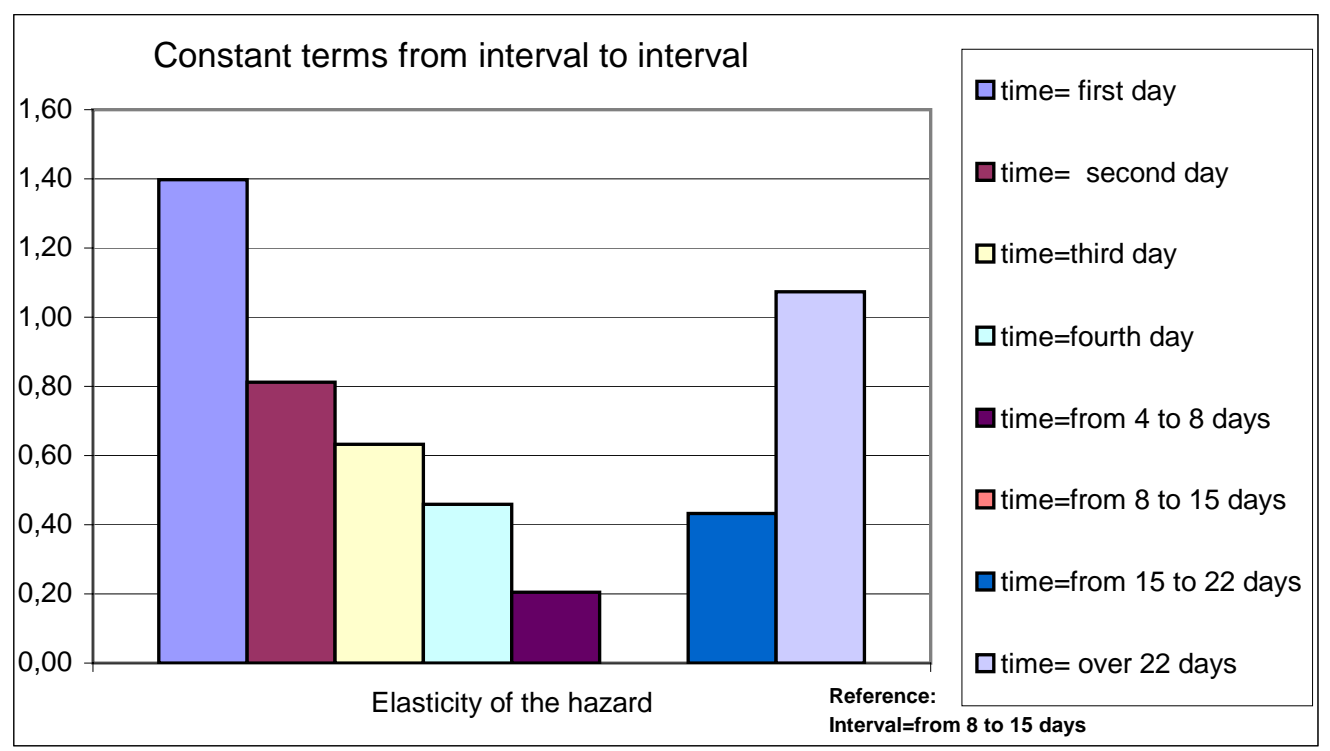

Table 3:

\begin{tabular}{|c|c|c|c|c|c|c|c|}
\hline \multirow[t]{2}{*}{ Independent variables } & \multicolumn{7}{|c|}{ Coefficients } \\
\hline & (1) & $(2)$ & (3) & (4) & (5) & (6) & (7) \\
\hline Main regional hospital & $\begin{array}{l}0.280^{* *} \\
{[0.119]}\end{array}$ & $\begin{array}{c}0.264 \\
{[0.207]}\end{array}$ & $\begin{array}{l}-0.069 \\
{[0.326]}\end{array}$ & - & - & $\begin{array}{c}0.166 \\
{[0.427]}\end{array}$ & - \\
\hline Local public & $\begin{array}{r}0.068 \\
{[0.247]}\end{array}$ & $\begin{array}{l}0.0920 \\
{[0.309]}\end{array}$ & $\begin{array}{c}0.068 \\
{[0.361]}\end{array}$ & $\begin{array}{c}0.212 \\
{[0.225]}\end{array}$ & - & $\begin{array}{c}0.164 \\
{[0.356]}\end{array}$ & $\begin{array}{l}-0.001 \\
{[0.432]}\end{array}$ \\
\hline Not-for-profit & - & - & - & $\begin{array}{c}-0.280^{* *} \\
{[0.122]} \\
\end{array}$ & - & - & $\begin{array}{l}-0.166 * \\
{[0.087]}\end{array}$ \\
\hline For-profit & $\begin{array}{l}-1.546 * * \\
{[0.785]}\end{array}$ & $\begin{array}{c}-1.551 * \\
{[0.792]}\end{array}$ & $\begin{array}{c}-1.572 * \\
{[0.812]}\end{array}$ & $\begin{array}{c}-1.402 * * \\
{[0.679]}\end{array}$ & - & $\begin{array}{l}-0.992 * \\
{[0.539]}\end{array}$ & $\begin{array}{l}-1.158 * \\
{[0.696]}\end{array}$ \\
\hline $\begin{array}{l}\text { Hospital ability to perform } \\
\text { innovative procedures }\end{array}$ & - & $\begin{array}{l}0.050 \\
{[.540]}\end{array}$ & $\begin{array}{c}-0.101 \\
{[0.462]} \\
\end{array}$ & - & - & $\begin{array}{c}0.728 \\
{[0.683]}\end{array}$ & $\begin{array}{c}0.728 \\
{[0.683]} \\
\end{array}$ \\
\hline Innovative procedure's rate & - & - & $\begin{array}{c}0.257 \\
{[0.759]}\end{array}$ & - & - & $\begin{array}{c}1.197 \\
{[1.035]}\end{array}$ & $\begin{array}{c}1.197 \\
{[1.035]}\end{array}$ \\
\hline Care unit size & - & & $\begin{array}{c}0.002 \\
{[0.001]}\end{array}$ & - & - & $\begin{array}{c}0.003 \\
{[0.002]}\end{array}$ & $\begin{array}{c}0.003 \\
{[0.002]}\end{array}$ \\
\hline Average age of inpatients & - & - & - & - & $\begin{array}{l}0.151^{* *} \\
{[0.595]}\end{array}$ & $\begin{array}{l}0.231 * * \\
{[0.108]}\end{array}$ & $\begin{array}{c}0.231^{* *} \\
{[0.108]}\end{array}$ \\
\hline Gender & - & - & - & - & $\begin{array}{l}-0.308 \\
{[2.059]}\end{array}$ & $\begin{array}{l}-1.156 \\
{[1.789]}\end{array}$ & $\begin{array}{l}-1.156 \\
{[1.789]}\end{array}$ \\
\hline Intercept & $\begin{array}{c}-10.344^{* * *} \\
{[0.111]}\end{array}$ & $\begin{array}{c}-10.377^{* * *} \\
{[0.371]}\end{array}$ & $\begin{array}{c}-10.455 * * * \\
{[0.387]}\end{array}$ & $\begin{array}{c}-10.488 * * * \\
{[0.660]}\end{array}$ & $\begin{array}{c}-21.049 * * * \\
{[4.291]}\end{array}$ & $\begin{array}{c}-27.069 * * * \\
{[8.020]}\end{array}$ & $\begin{array}{c}-26.903^{* * *} \\
{[8.075]}\end{array}$ \\
\hline R-squared & 0.0340 & 0.0341 & 0.0355 & 0.0340 & 0.0408 & 0.078 & 0.078 \\
\hline
\end{tabular}

Standard errors in brackets

* significant at $10 \%$; ** significant at $5 \%$; *** significant at $1 \%$

PMSI Database: 28,410 stays and 287 hospitals, 1997 
Table 4:

Dependent variable: in-death rate

\begin{tabular}{|l|c|}
\hline \multicolumn{1}{|c|}{ Independent variables } & Coefficients \\
\hline Average age by hospital & $\begin{array}{c}0.0113^{* * *} \\
{[0.001]}\end{array}$ \\
\hline $\begin{array}{l}\text { Proportion of male patient by } \\
\text { hospital }\end{array}$ & $\begin{array}{c}0.013 \\
{[0.048]}\end{array}$ \\
\hline Intercept & -0.658 \\
\hline Prob $>$ F & {$[0.062]$} \\
\hline R-squared & 0.0000 \\
\hline
\end{tabular}

Standard errors in brackets

* significant at $10 \%$; ** significant at $5 \%$; ** significant at $1 \%$

Table 5:

\begin{tabular}{|l|c|c|c|c|}
\hline & \multicolumn{4}{|c|}{ Variance between-hospital by hospital ownership: } \\
inefficiency heterogeneity \\
\hline Independent variables & $(1)$ & $(2)$ & $(3)$ & $(4)$ \\
\hline Main regional hospital & 0.25 & 0.26 & 0.29 & 0.68 \\
Local public & 2.85 & 2.86 & 2.86 & 2.86 \\
Not-for-profit & 0.54 & 0.56 & 0.54 & 0.58 \\
For-profit & 6.23 & 6.23 & 6.24 & 6.23 \\
\hline
\end{tabular}

(1): Hospital ownership.

(2): Hospital ownership, hospital ability to perform complex or/and innovative procedures.

(3): Hospital ownership, hospital ability to perform complex or/and innovative procedures and the rate of innovative procedure.

(4): Hospital ownership, hospital ability to perform complex or/and innovative procedures, the rate of innovative procedure and care unit size. 